\title{
Impact of COVID-19 on Food Systems and Rural Livelihoods in Nigeria
}

\section{COVID-19 Country Report - September 2020}

Prepared by Adebayo B. Aromolaran and Milu Muyanga

\section{Introduction}

This report presents an early assessment of the impacts of the COVID-19 pandemic on agricultural commercialisation, food and nutrition security, labour and employment, and poverty and well-being in rural Nigeria. Data was collected from a stratified random sample of 110 respondent households drawn from five Local Government Areas (LGAs) in Ogun (ljebu East, Obafemi Owode, and Imeko Afon) and Kaduna (Chikun and Soba) States. At the time of the survey, these LGAs had reported a small number of COVID-19 cases. The survey data is complemented by insights from five in-depth key informant interviews conducted in the LGAs. The APRA COVID-19 data collection will be carried out over three rounds. This report presents insights obtained from the first round implemented during mid-July 2020.

\section{Context}

Since the outbreak of COVID-19 in Africa, there have been serious concerns about the impact of the pandemic on agrifood systems - given that most of the population depends directly or indirectly on agriculture for their livelihoods. These concerns are compounded by the fragile state of the continent's health and food systems. The first case of COVID-19 in Nigeria was reported on February 27 2020. By the time this assessment was completed, some 50,964 cases and 992 deaths related to COVID-19 had been recorded.

\section{Health and disease}

About $12 \%$ of respondents knew someone who had COVID-19 symptoms in their village and $21 \%$ said they had heard of confirmed cases of COVID-19 in their LGAs.

As much as $38 \%$ of households were unable to access health care services because of the lockdown measures that restricted movement across the country. It emerged from the key informant interviews that the lockdowns may have resulted in many illnesses and deaths that were unrelated to COVID-19.

"At the local market, the price of farm produce was low because the buyers were not allowed to come to the market, so there was a glut of produce and no money in circulation. The situation is reversed in the regional markets because of restrictions on the transportation of goods, especially interstate." Chairman, Farmers' Association, Obafemi Owode LGA, Ogun State, Nigeria

\section{Farm inputs and marketing}

The COVID-19 period is associated with a reduction in labour availability and increased labour costs. About 79\%

\section{Key findings}

- Movement restrictions resulted in reduced availability and high cost of farm labour, which in turn, resulted in a decline in land area cultivated.

- The ability of farmers to sell their produce declined due to COVID-19 restrictions on the movement of traders from outside the communities, resulting in over-supply and lower farm gate prices.

- Only about half of households engaged their children in schoolwork during the COVID-19 lockdown.

- Religious organisations were the most common source of assistance, but the majority of households did not get any form of COVID-19-related assistance.

- The majority of households reported decreased availability and higher prices of food items in the COVID-19 period.

- The majority of households experienced a decline in consumption of healthy and nutritious food in terms of frequency, quantity and quality.

of households reported decreased activities on their farms as a result of reduced labour availability due to movement restrictions, and the high cost of labour. Reduced availability of farm inputs (e.g. fertilisers and agrochemicals) was also reported.

The ability to sell farm produce also declined. About $71 \%$ of households reported a reduced ability to sell at the farm gate, while $86 \%$ faced increased transportation costs. About $82 \%$ reported a decline in the number of buyers coming to purchase farm produce directly from them.

\section{Changes in prices (\%)}

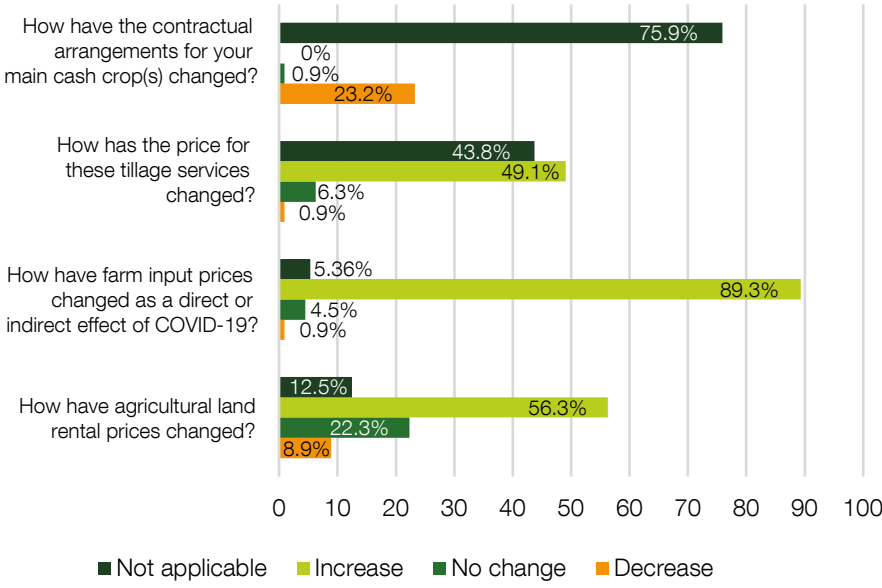




\section{Availability of services for agricultural production}

The majority of respondents reported a decline in the availability of rental land, purchased farm inputs, tillage services, extension services, and credit facilities since the start of the COVID crisis in Nigeria. This led to an increase in the price of land, inputs and tillage services in their communities.

\section{Food and nutrition security}

In the first three months of the COVID-19 pandemic, over $82 \%$ of respondent households were unable to eat healthy and nutritious food because of a lack of resources.

- Most households (81\%) ate only a few kinds of foods, implying declining dietary diversity.

- Some $78 \%$ of households skipped meals or ate less than they thought they should due to inadequate resources. This was because many households (65\%) ran out of food stock.

- Nearly one out of five households (18\%) reported having members go hungry for a whole day after the COVID-19 crisis began.
We also asked respondents how their cost of living had changed since the start of COVID-19. The majority indicated that their overall costs had increased considerably.

Change in cost of living (\%)

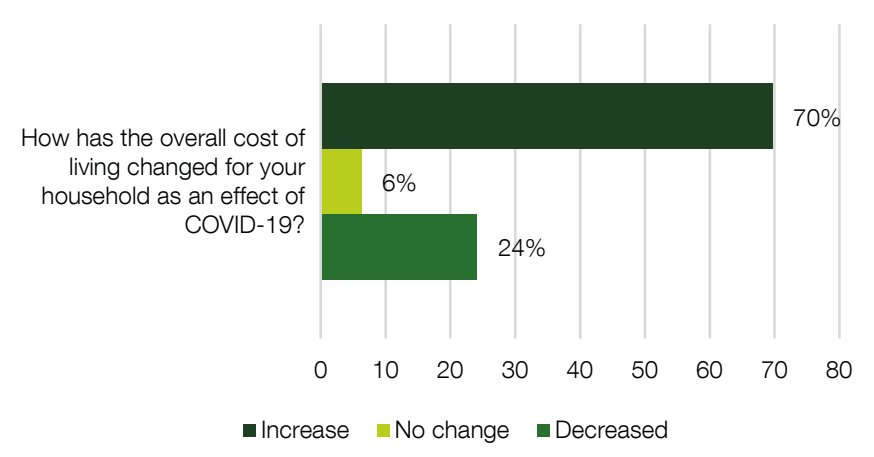

\section{Responses to the threat of COVID-19}

In response to the COVID-19 pandemic, the federal government instituted several regulations that may have had unintentional negative impacts on the livelihoods of households. These included movement restrictions and the shutdown of schools. Only $54 \%$ of girls and $46 \%$ of boys continued with their schoolwork at home during COVID-19 school closures, despite the government-sponsored educational television, radio and digital programmes. Furthermore, participation in farming activities declined for $79 \%$ of households, while off-farm employment opportunities were also severely curtailed, both inside and outside the village.

The majority of sampled households (51\%) did not receive any form of COVID-19-related assistance during the first three months of the pandemic. A small number of households reported receiving assistance from religious organisations (17\%), government (15\%) and family members (10\%).

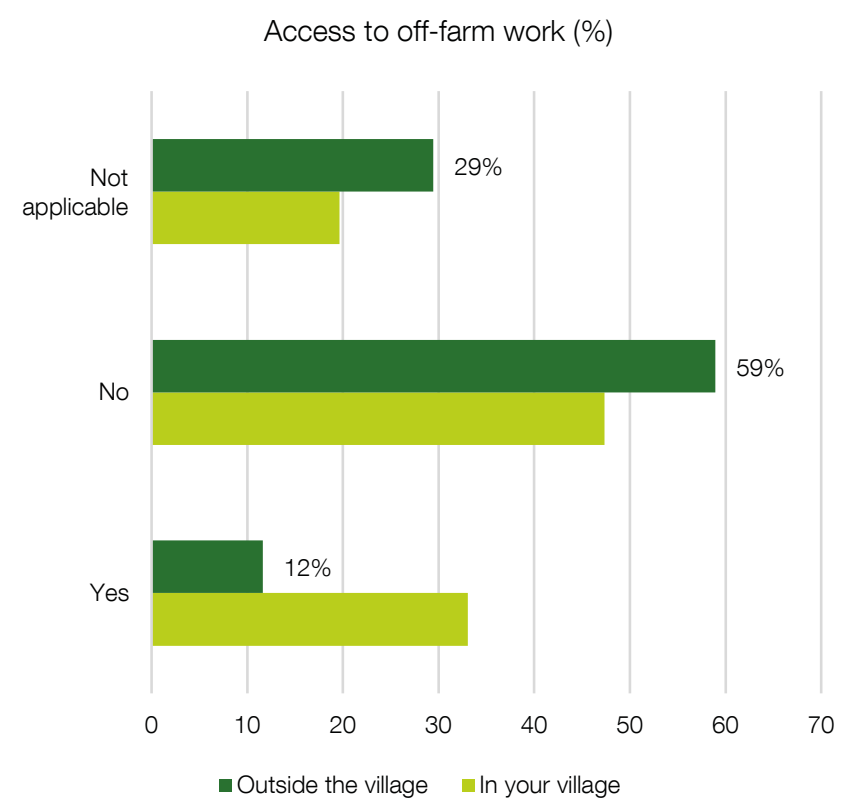
International licence (CC BY-NC-ND), which permits use and distribution in any medium, provided the original authors and source are credited, the work is not used for commercial purposes, and no modifications or adaptations are made.

If you use the work, we ask that you reference the APRA website (www.future-agricultures.org/apra/) and send a copy of the work or a link to its use online to the following address for our archive: APRA, Future Agricultures, University of Sussex, Brighton BN1 9RE, UK (apra@ids.ac.uk) 